\title{
THE NATIONAL ACADEMY'S 1987 REPORT ON FOSSIL COLLECTING
}

\author{
RAUP, David M., Dept. of Geophysical Sciences, University of Chicago, \\ Chicago, IL 60637, U.S.A.
}

In the debate over government regulation of fossil collecting on public lands, well-meaning and informed people often arrive at opposing positions. Indeed, both sides in the debate have legitimate and powerful arguments, which may explain the ease with which strong views are adopted after only a brief introduction to the problem. Important fossils are destroyed or lost to science by sloppy collecting, destructive handling, or simply by sale into remote private collections. On the other hand, many of our most important Lagerstätten are known well only from the efforts of private and commercial collectors (e.g., Solnhofen, Mazon Creek).

Ten years ago, the National Academy's Committee on Guidelines for Paleontological Collecting grappled with the problem of regulation through a series of full and often intense meetings over an 18-month period. The Committee's 13 members represented a spectrum of paleontological experience: government, academia, museums, and commercial collecting, as well as the principal taxonomic specialities (VP, IP, micropaleontology, and paleobotany). There was even a lawyer, a politician, and a strip-miner (but not, unfortunately, a hobby collector). Because of the sensitivity of fossil vertebrates, VP occupied four of the 13 "seats." The Committee members started out with widely divergent positions, yet a strong consensus was achieved, with results which startled many of us. The final votes on the ten recommendations were unanimous.

The dominant theme of the Committee's report (National Academy Press, 1987 ) is that the disadvantages of regulation usually outweigh the benefits: " ... the science of paleontology is best served by unimpeded access to fossils and fossilbearing rocks in the field." (page 2). Furthermore, the report explicitly denied the commonly-asserted analogy between paleontology and archeology, arguing that the protection problem for fossils is far different from that for human remains. Despite the generally free-access stance adopted by the Committee, there were important caveats. The report urged that permits be required for all commercial collecting, for collecting in national parks, and for fossil quarries. Further, several of the recommendations suggested guidelines for the protection of scientifically important fossils after collecting. The report implied, but did not state explicitly, that hobby collecting should be left unregulated. However, due to the difficulty of defining the boundary between hobby and commercial collecting, the role of the amateur fossil collector was left in limbo. In future discussions, this aspect deserves closer attention. 